\title{
CARTOGRAFIAS DA PANDEMIA: REFLEXÕES SOBRE A PRODUÇÃO DE MAPAS NO ENFRENTAMENTO DA COVID-19
}

\author{
CARTOGRAPHIES OF PANDEMIC: REFLECTIONS ON THE MAP PRODUCTION AGAINST \\ COVID-19
}

Anselmo César Vasconcelos BEZERRA, Emerson Soares dos SANTOS², Fernando Ramalho Gameleira SOARES³

Artigo recebido em 15/10/2020, aceito em 30/11/2020, publicado em 18/12/2020

\author{
Palavras-chave: \\ Novo Coronavírus; \\ Geografia da \\ Saúde; Saúde \\ Pública.
}

Keywords: New Coronavirus; Health Geography; Public Health.

\section{RESUMO}

O objetivo desta reflexão é apresentar uma discussão sobre a produção cartográfica durante a Pandemia de COVID-19. Para tanto, realizou-se um breve resgate sobre o uso dos mapas no campo da saúde pública, destacando a importância do rigor técnico-científico na construção desses insumos estratégicos à tomada de decisão. Assim, exemplificamos os riscos da construção de mapas sem critérios adequados, seja porque geram leituras equivocadas por parte da população em geral, ou porque influenciam decisões importantes, no contexto da Pandemia. Conclui-se que com o avanço da tecnologia e a disponibilidade massiva de informações, a produção de mapas se popularizou em vários segmentos da sociedade. Entretanto, a confecção desses produtos deve se basear nos princípios básicos da cartografia para que os mapas sirvam, de fato, para auxiliar no enfrentamento da Pandemia da COVID19.

\section{ABSTRACT}

The reflection presented aims to develop a discussion about cartographic production in the COVID-19 Pandemic. To achieve this objective, a brief discussion was held on the use of maps in the domain of public health, highlighting the relevance of technical-scientific rigor in the construction of these strategic inputs for decision making. Thus, we exemplify the map production hazard based on inadequate criteria, either because it leads to a wrong apprehension by the population, or because it biases important decisions related to Pandemic issues. This allows the conclusion that in the face of technological advancement and massive information availability, the production of maps became popular in various social groups. However, the development of these products must be based on cartographic principles in such a manner that the maps can serve, in fact, to support the confrontation of the COVID-19 Pandemic.

\footnotetext{
${ }^{1}$ Professor do Instituto Federal de Educação, Ciência e Tecnologia de Pernambuco (IFPE) nos cursos de Gestão Ambiental, Licenciatura em Geografia (Graduação) e Sustentabilidade Urbana e Educação Ambiental (Pós-graduação). E-mail: anselmo@recife.ifpe.edu.br

2 Professor da Universidade Federal do Mato Grosso. E-mail: emer@ufmt.br

${ }^{3}$ Geógrafo do Instituto Brasileiro de Geografia e Estatística. E-mail: fernando.soares@ibge.gov.br
} 


\section{INTRODUÇÃO}

O uso de mapas para descrever e entender fenômenos no campo da saúde pública é bastante antigo (Koch \& Koch, 2005). Trabalhos de referência, como os escritos de John Snow (1990), Max Sorre (1951) e Josué de Castro (1995) demonstraram como a comunicação através dos mapas pode revelar problemas de saúde, ou que afetam a saúde, e tem um caráter estratégico e aplicado. Estes trabalhos têm como fio condutor o raciocínio geográfico. Trata-se de um modo de pensar espacial muito caro aos geógrafos, mas que ao longo do tempo também foi incorporado por sanitaristas e epidemiologistas. Os mapeamentos realizados por estes três autores tinham uma característica comum: a apresentação espacial do problema como subsídio para ação.

No contexto da atual Pandemia de COVID-19, a construção, análise e divulgação de mapas certamente atingiram os maiores patamares da história, isso porque na era do meio técnico-científicoinformacional, que para Santos (2002) é a expressão geográfica da globalização, a quantidade de informações e recursos disponíveis para a produção desse volume de documentos cartográficos é infinitamente superior ao que dispunham pesquisadores de outras épocas.

Se por um lado esse avanço tecnológico e informacional é positivo, pois populariza e difunde a importância dos mapeamentos e das análises espaciais sobre os fenômenos que impactam a sociedade, por outro lado pode ser perigoso, pois mapas mal construídos e análises superficiais ou equivocadas podem causar problemas no processo de tomada de decisão. No contexto da Pandemia isso ganhou uma dimensão maior, visto que existe uma gama de dados disponíveis, uma diversidade de softwares para criar mapas e vários tipos de mídias para divulgação do que denominamos Cartografias da Pandemia.

Contudo, há um problema na difusão de produtos cartográficos de forma generalizada durante a Pandemia da COVID-19, pois diferentemente dos mapas e das análises construídos pelos autores supracitados, uma parte da produção de mapas para análise espacial da COVID-19, construída por profissionais das mais diferentes especializações e divulgados, muitas vezes com autoridade científica, não utilizam critérios básicos da cartografia ou do raciocínio geográfico. Assim, algumas produções chegam à população através das mídias convencionais, redes sociais e aplicativos criados especificamente para divulgação de informações sobre a Pandemia. Da mesma forma que uma parte da população se familiarizou com os mapas dos aplicativos de mobilidade e delivery, está se acostumando a ver os mapas sobre à difusão da COVID-19 nos diferentes meios de comunicação. Isto não seria problemático se parte desses mapas não apresentassem resultados equivocados que induzem às pessoas a tomar decisões a partir da percepção da doença. 
Assim, o objetivo desta reflexão é discutir sobre a produção cartográfica na Pandemia, ressaltando a importância do rigor na construção de mapas e destacando exemplos, nos quais o uso de mapas mal elaborados podem impactar a tomada de decisão e a percepção social do fenômeno. Para tanto, recorreu-se a uma análise empírica de mapas publicados em diferentes mídias, redes sociais e aplicativos, durante a Pandemia.

\section{O RIGOR NA PRODUÇÃO DE MAPAS}

Existem componentes essenciais que devem permear a elaboração de qualquer mapa que tenha como objetivo apoiar decisões no campo da saúde: uma análise epidemiológica ou de saúde pública, e um raciocínio geográfico que una teoria e método. A ausência destes componentes no mapeamento da situação, evolução e difusão da COVID-19 e seus impactos, corre o risco de ser incompleto ou até errado. Esse argumento não é uma defesa das formas de produzir mapas do passado, nem mesmo uma reivindicação de exclusividade corporativista, pois existem inúmeros trabalhos com rigor acadêmico e compromissados com 0 enfrentamento da Pandemia desenvolvidos por diferentes especialidades. Entretanto, verifica-se também uma enorme produção descontextualizada e desconectada dos saberes geográficos e de saúde pública.

Os mapas são poderosos instrumentos de comunicação, cujo processo completo passa necessariamente por duas etapas: a elaboração e a leitura (Board, 1975). Terá sucesso na comunicação se a primeira etapa (elaboração) seguir os parâmetros recomendados na teoria da representação cartográfica, discutida com profundidade por Bertin (1977) através da Semiologia gráfica. A consequência em seguir estes critérios é a minimização do risco de a segunda etapa da comunicação (leitura) ser polissêmica.

Para Monmonier (1991) todo mapa, antes de tudo, é uma mentira. Ele faz essa observação a partir da constatação de que o mapa é apenas uma representação da realidade, sempre reduzida às informações disponíveis para retratar determinado espaço ou fenômeno. Contudo, o autor considera que essa mentira é inerente a toda produção cartográfica, o que não acontece em outras duas situações: quando o mapeador erra por ignorância ou deficiência na formação cartográfica, ou por intenções descomprometidas com o real objetivo do mapeamento.

Nos softwares de geoprocessamento e de cartografia digital são disponibilizadas diversas formas de agrupamento de dados, sejam eles qualitativos ou quantitativos, assim como um grande conjunto de símbolos e cores. Ocorre que muitas vezes, o mapeador opta por escolher o modo default de representação, e isso pode ocasionar a criação de uma informação parcialmente (ou totalmente) falsa. É bastante comum nessas Cartografias da Pandemia encontrar mapas em que as variáveis visuais foram utilizadas de maneira equivocada. 
Para exemplificar essa problemática apresentaremos erros comuns na representação cartográfica relacionada com a Pandemia. Primeiramente, tem se observado o constante uso da metodologia Kernel (Shawe-Taylor \& Cristianini, 2004) para representar "áreas quentes" da COVID-19 na escala intraurbana. Sabe-se que o uso desta metodologia, como uma técnica cujo princípio é a estimação de valores para a interpolação de dados no espaço, requer alguns critérios específicos para não gerar resultados distorcidos. No início da Pandemia, esta técnica foi intensamente utilizada, porém pressupostos importantes, seja do ponto de vista da estatística, da epidemiologia, ou mesmo da geografia, não foram levados em conta. Foi divulgada uma grande quantidade de mapas que mostravam áreas classificadas como de risco à contaminação pela doença. $O$ risco de contaminação por um vírus está diretamente relacionado com a base populacional, e na quase totalidade destes mapas de Kernel, não foi utilizada esta informação, tanto na execução da técnica, como na representação. Nesse sentido, a denominação 'área de risco' é equivocada. Além disso, há o fator da subnotificação da doença, que não é passível de representação, o que pode induzir o leitor do mapa a considerar que "áreas não-quentes" estivessem livres do risco. Segundo Luiz e Cohn, (2006), o risco epidemiológico pode ser definido como a probabilidade de ocorrência de um determinado evento relacionado à saúde, estimado a partir do que ocorreu no passado recente. Assim, calcula-se o risco quantificando o número de vezes que o evento ocorreu dividido pelo número potencial de eventos que poderiam ter acontecido.

Outro uso equivocado da cartografia para representar casos da COVID-19 no espaço intraurbano refere-se à localização dos casos por endereço de residência. Do ponto de vista ético, informações pessoais, de qualquer natureza, não podem ser reveladas, porém no início da Pandemia, muitos mapas, alguns inclusive oriundos de órgãos de governo, apresentaram a localização dos casos confirmados e óbitos. No exemplo do Estado de Pernambuco, este equívoco foi corrigido em sequência, passando a utilizar um erro de 50 metros dos locais de ocorrência do evento (https://dados.seplag.pe.gov.br/apps/corona.html\#mapas). Mapas que identificam a residência podem ajudar na estigmatização dos locais referenciados, como se a representação de um ponto no mapa já significasse um "lugar doente" ou insalubre. E sabe-se que isso não é verdadeiro, visto que a notificação do caso pode ter vários desfechos, desde pessoas com sintomas leves em isolamento domiciliar, pessoas internadas em hospitais, ou até casos mais graves que terminam em óbito. A geolocalização do fenômeno, neste caso, além de indevida, pode gerar reações desproporcionais em relação ao tamanho real do risco.

Mais uma forma de elaboração de mapas totalmente impertinente é a sobreposição espacial dos casos da COVID-19 com temas que não têm qualquer relação com a sua incidência ou difusão espacial, desconsiderando a escala de análise. Há mapas em que os casos representados, agregados em área, ou em superfície de áreas quentes e frias, são, por exemplo, relacionados com tipos de climas ou rede hidrográfica 
no espaço intraurbano. Este tipo de abordagem pode induzir o leitor a estabelecer nexos causais entre elementos totalmente dissociados.

\section{AS CONSEQUÊNCIAS DOS MAPAS SEM RIGOR}

No que se refere à Pandemia e as inúmeras possibilidades de mapeamentos desse fenômeno, as situações discutidas por Monmonier (1991) estão presentes em alguns produtos que são apresentados à sociedade, influenciando as decisões individuais e do poder público. Isso acaba por gerar uma nova forma de vulnerabilidade perante a Pandemia, dado que interpretações equivocadas sobre os mapas, ou mapas com informações imprecisas, por ignorância ou intencionalidade, induzem ao erro, podendo ocasionar pânico ou relaxamento social. Outras questões, como inconsistência de informações nos bancos de dados e mudanças de metodologia na alimentação dos sistemas de informação também acarretaram dificuldades de compreensão da magnitude real do fenômeno.

Em função das medidas de distanciamento social adotadas praticamente em todo o mundo, as pessoas passaram a ficar mais tempo em casa, recebendo uma intensa produção de notícias sobre a Pandemia, que por vezes apresenta algum tipo de mapa. Assim também são as informações disponíveis nos diversos aplicativos de celular criados para informar sobre o status da pandemia.

Inicialmente, de maneira intuitiva, ao receber esse tipo de informação tendemos a acreditar naquilo que está demonstrado, especialmente quando a origem da informação é de um grupo de pesquisa, de um laboratório ou mesmo de uma empresa, mas também porque a maior parte da população não tem treinamento adequado para interpretar criticamente as informações apresentadas, levando em conta os limites técnicos da representação cartográfica ou dados epidemiológicos. Assim, sem crítica, decisões podem ser tomadas, como por exemplo, deixar de ir ao supermercado mais próximo da residência porque o mapa que recebeu no aparelho de celular mostra uma mancha vermelha indicando algum grau de risco sobre 0 local onde o supermercado está situado, ou mesmo acreditar que está vulnerável, porque viu um ponto plotado no mapa que indica um caso confirmado a poucos metros de sua casa. Situações como essas parecem banais, mas no contexto pandêmico ganham dimensões diferenciadas, pois influenciam decisões pessoais e legitimam um retrato que pode não ser real.

Outra consequência muito séria da produção dos mapas sem rigor e/ou análises críticas é a possibilidade de influenciar os tomadores de decisão. Uma vez compreendido que os mapas auxiliam os gestores a ter uma visão espacial do fenômeno, atenta-se para o risco de mapas mal elaborados ou com análises equivocadas guiarem decisões importantes de autoridades, seja do ponto de vista econômico, ou do ponto de vista sanitário. 


\section{CONCLUSÕES}

O objetivo de refletir sobre a produção de mapas no contexto da Pandemia vai muito além da crítica meramente acadêmica, uma vez que os instrumentos cartográficos podem ter um impacto direto na gestão da emergência em saúde pública. Assim, o grande número de representações espaciais da COVID-19 e os fatores associados à Pandemia são importantes, pois subsidiam decisões e ajudam na compreensão do fenômeno. Entretanto, ressalta-se que as formas imprecisas ou equivocadas de produção de mapas também geram consequências perigosas, especialmente por se tratar de um problema de saúde pública sem precedentes na história contemporânea.

Com o advento da globalização, a produção de informações ocupou uma centralidade no cotidiano da sociedade. No contexto da Pandemia, isso ganhou uma relevância maior, visto a necessidade das pessoas se informarem sobre um fenômeno novo, mas também pela capacidade das instituições em produzir informações e disponibilizá-las das mais variadas formas. Assim, os mapas são ferramentas poderosas que podem servir tanto como instrumental essencialmente positivo na apreensão dos diversos aspectos que envolvem a Pandemia e, de outra forma, contribuir negativamente para criar e reforçar estereótipos ou, apressadamente, oferecer falsas justificações científicas para a tomada de decisão dos cidadãos comuns e dos agentes públicos, responsáveis pela proposição de estratégias no enfrentamento à Pandemia.

\section{REFERÊNCIAS}

Board, C. (1975). Os mapas como modelos. In: Chorley, Richard J. Modelos físicos e de informação em Geografia, Rio de Janeiro: Livros Técnicos e Científicos, p. 139-184.

Bertin, J. (1977). La graphique et traitement graphique de l'information, Paris: Flamarion.

Castro, J. (1995). Geografia da fome. São Paulo: Círculo do Livro.

Koch, T., \& Koch, T. (2005). Cartographies of disease: maps, mapping, and medicine [Cartografias das doenças: mapas, mapeamento e medicina]. Redlands, CA: Esri Press.

Luiz, Olinda do Carmo, \& Cohn, Amélia. (2006). Sociedade de risco e risco epidemiológico. Cadernos de Saúde Pública, 22(11), 2339-2348.

Doi:10.1590/S0102-311X2006001100008
Monmonier, M. (1991). How to Lie with maps. Chicago, EUA: University of Chicago.

Santos, M. (2002). A Natureza do espaço: técnica e tempo, razão e emoção. São Paulo: EDUSP.

Shawe-Taylor, J., \& Cristianini, N. (2004). Kernel methods for pattern analysis. Cambridge: University press.

Snow, J. (1990). Sobre a Maneira de Transmissão do Cólera. 2a ed. São Paulo: HUCITEC-ABRASCO.

Sorre M. (1951). Les fondements de la géographie humaine. Primeiro tomo: Les fondements biologiques (Essai d'une écologie de l'homme). 3 ed. Paris: Armand Colin. 